\title{
ESCOLA E SOCIEDADE DE CONSUMIDORES: UM ESTUDO COM CRIANÇAS “CATADORAS”
}

\author{
Daiane Martins Bocasanta* \\ Gelsa Knijnik**
}

RESUMO: O artigo apresenta resultados de uma pesquisa cujo objetivo foi analisar os significados atribuídos à "catação" de resíduos sólidos recicláveis por um grupo de alunos de uma escola municipal de São Leopoldo que tinham sua existência vinculada a essa atividade. $\mathrm{O}$ material de pesquisa foi composto por entrevistas, feitas com oito crianças, desencadeadas por seus desenhos e registros em diário de campo. O estudo tem como referencial teórico o pensamento de Michel Foucault, as ideias do "Segundo" Wittgenstein e a obra de Zygmunt Bauman. A análise possibilitou inferir que aquelas crianças: a) participavam da catação, sobretudo, porque desejavam consumir, estando integrados à sociedade de consumo via uma "inclusão diferenciada"; e b) praticavam jogos de linguagem matemáticos que possuíam especificidades, mesmo que guardassem semelhanças de família com aqueles que constituem a matemática escolar.

Palavras-chave: Crianças Catadoras; Jogos de Linguagem; Sociedade de Consumidores.

\footnotetext{
*Doutora em Educação pela Universidade do Vale do Rio dos Sinos (UNISINOS) e Professora na Universidade Federal do Rio Grande do Sul (UFRGS). E-mail: daianebocasanta@gmail.com

* *Doutora em Educação pela Universidade Federal do Rio Grande do Sul (UFRGS); Professora titular da Universidade do Vale do Rio dos Sinos (UNISINOS) e Pesquisadora do Conselho Nacional de Desenvolvimento Científico e Tecnológico (CNPq). E-mail: gelsa.knijnik@gmail.com
} 


\section{SCHOOL AND CONSUMER SOCIETY: A STUDY WITH RECYCLING CHILDREN}

ABSTRACT: This article presents the results of a study whose main purpose was to analyze the meanings attributed to the recycling of solid residues by a group of children of a municipal school located in Sao Leopoldo, Brazil. These schoolchildren had their existence tied to that work. Empirical data was composed by interviews, conducted with eight children, which were based on pictures that they had previously drawn and notes registered in field diary. The theoretical framework of this research is based on Michel Foucault's thinking, Wittgenstein's later ideas and the work of Zygmunt Bauman. It was possible to infer from the research data analysis that those children participated in the recycling work mainly because they wanted to consume, being integrated into consumer society via "differential inclusion"; and that they practiced specific mathematical language games, even though they maintained family resemblance with those that constitute school mathematics.

Keywords: Recycling Children; Language Games; Consumer Society.

\section{INTRODUCุÃO}

Este artigo apresenta resultados de uma pesquisa cujo objetivo foi analisar os significados atribuídos à "catação de resíduos sólidos" por um grupo de crianças, estudantes de $2^{\circ}$ ano de uma escola municipal de São Leopoldo, RS, cuja existência estava vinculada a essa atividade ${ }^{2}$, examinando os jogos de linguagem que a constituíam.

Um amplo espectro de áreas do conhecimento tem abordado a temática da reciclagem de resíduos sólidos. Entre esses estão os que analisam ações públicas ou processos organizativos desses grupos - como, por exemplo, os de Michelotti (2006), Arenhart (2006) e Andersson (2005) - e aqueles que enfocam especificamente processos educativos com pessoas envolvidas nas atividades de reciclagem - como os de Feitosa (2005), Fischer (2006), Souza (2008) e Mello (2003).

Do ponto de vista teórico, o presente estudo tem como alicerce ferramentas teóricas advindas do pensamento de Zygmunt Bauman, Michel Foucault e Ludwig Wittgenstein. Tais ferramentas e a consistência de operação das mesmas de modo articulado são apresentadas, de modo breve, na seção 1. Porém, a enunciação dos aportes teóricos que embasam a investigação não se esgota nessa seção. Em efeito, ao longo do texto, discussões de cunho mais teórico são introduzidas para que o exercício analítico sobre o material de pesquisa ganhe maior densidade. Compõem o material analisado entrevistas realizadas com oito crianças com idades que variavam entre seis e onze anos, 
desencadeadas por desenhos que haviam realizado previamente; anotações de observações e falas registradas em diário de campo e informações geradas numa visita ao aterro sanitário. O lócus da investigação - o bairro Santa Marta - e a produção do material de pesquisa são descritos na segunda seção do trabalho. Na descrição, excertos desse material empírico produzido nas diferentes fases do estudo são apresentados. Com isso, queremos destacar que tal descrição foi construída ao longo do próprio trabalho de campo, sendo sua análise central para a elaboração da pesquisa. Neste trabalho serão destacados dois dos resultados produzidos no estudo, discutidos na seção 3.

O texto encerra com uma breve discussão sobre possíveis contribuições do estudo para os questionamentos que hoje fazemos sobre a sala de aula e as práticas pedagógicas que ali se desenvolvem, principalmente no âmbito da matemática.

\section{DO ALICERCE TEÓRICO DO ESTUDO}

O estudo tem como alicerce teórico noções advindas do pensamento dos filósofos Michel Foucault e Ludwig Wittgenstein - em sua obra de maturidade - e do sociólogo Zygmunt Bauman. Assim, nesta seção destacaremos sucintamente as contribuições desses pensadores que foram úteis para a construção da pesquisa: as noções de relações de poder, contraconduta e neoliberalismo de Foucault; consumidores falhos, sociedade de consumidores e sociedade de produtores de Bauman; e jogos de linguagem, gramática, semelhanças de família e formas de vida da obra tardia de Wittgenstein.

$\mathrm{Na}$ perspectiva foucaultiana, o poder não emana de nenhum centro específico, visto que não seria algo que poderíamos adquirir, arrebatar, compartilhar, guardar ou deixar escapar. O poder estaria em toda parte e se exerceria a partir de diversos pontos e em relações desiguais e móveis, não constituindo, assim, uma relação binária do tipo dominados e dominadores (FOUCAULT, 1988). Em todas as esferas da vida cotidiana estaríamos envolvidos em relações de poder, pois ele "[...] está em toda parte; não porque englobe tudo e sim porque provém de todos os lugares [...]" (FOUCAULT, 1988, p. 89). 
Um dos elementos importantes do pensamento foucaultiano sobre as relações de poder indica que, correlato a essas, existe necessariamente a possibilidade de resistência, pois se ela não existisse - seja violenta, de escape, uma manobra ou ainda uma estratégia para reverter a situação -, não se configurariam relações de poder (FOUCAULT, 2004): “[...] onde houver poder há resistência e, no entanto (ou melhor, por isso mesmo) esta nunca se encontra em posição de exterioridade em relação ao poder [...]" (FOUCAULT, 1988, p. 91).

Dando continuidade a essa tese, o filósofo analisa, no curso ministrado no Còllege de France em 1978, intitulado Segurança, Território e População, as revoltas de conduta correlativas do pastorado. Nesse curso, Foucault aborda a problemática do governo, enfatizando que em seus primórdios, o verbo governar não se referia à administração estatal e territorial mas, antes, à arte de conduzir ${ }^{3}$ alguém e também o seu contrário, ou seja, conduzir-se diferentemente àquela condução (CANDIOTTO, 2006, p. 71). Nesse sentido, o questionamento feito a qualquer tipo de governo não se daria apenas pela violência, mas principalmente pela mudança de atitude frente à questão do poder e da questão da problemática da verdade (CANDIOTTO, 2006, p. 71). Na aula ministrada em primeiro de março de 1978, Foucault (2008, p. 263-264) questiona-se:

Aquilo que chamei há pouco de resistências, recusas, revoltas, será que não poderíamos tentar encontrar uma palavra para [o] designar? Como designar esse tipo de revoltas, ou antes, essa espécie de trama específica de resistência a formas de poder que não exercem soberania e que não exploram, mas que conduzem?

Como resposta a esse questionamento, o filósofo francês elege o termo contraconduta, “[...] no sentido de luta contra os procedimentos postos em prática para conduzir os outros [...]” (FOUCAULT, 2008, p. 266). A contraconduta seria uma atitude crítica diante dos efeitos de verdade que justificariam o governo das condutas, sendo, portanto, uma condição para a não aceitação dos efeitos de poder presentes nos discursos tomados como verdadeiros (CANDIOT'TO, 2006, p. 71). Servindo-nos dessas formulações foi possível identificar, no exercício analítico realizado sobre o material de pesquisa, movimentos de contraconduta postos em ação pelos participantes 
do estudo, como forma de se contrapor aos baixos valores pagos pelo produto de seu trabalho, conforme será explicitado adiante, na terceira seção.

Acompanhando as discussões realizadas por Saraiva e Veiga-Neto (2009), Veiga-Neto (2002) e Marisa Costa (2006), estabelecemos uma interlocução entre ideias de Foucault e o pensamento do sociólogo polonês Bauman. Tal articulação mostrou-se consistente, uma vez que se pode identificar na obra de Bauman influência do pensamento foucaultiano (ALMEIDA; GOMES; BRACHT, 2009, p. 20).

Em seus livros da fase denominada por alguns autores de mosaica (ALMEIDA; GOMES; BRACHT, 2009, p. 37), Bauman aborda a questão do lixo e do consumo, demarcando que "[...] as novas formas de exclusão do refugo humano (dos estranhos) na modernidade líquida produzem mais um paradoxo: embora o refugo deva ser excluído, ele também é necessário [...]" (ALMEIDA; GOMES; BRACHT, 2009, p. 39). Numa sociedade de consumo, em que o prazer, o conforto e o esforço mínimo conformam a tônica da vida, os consumidores não são estimulados a realizar o serviço sujo da remoção do lixo produzido continuamente, visto que esse transtorno não combina com o consumidor. "O destino do refugo é o depósito de dejetos, o monte de lixo [...]” (BAUMAN, 2005, p. 20).

Como antes indicado, noções advindas do pensamento do período de maturidade de Wittgenstein também foram centrais para o estudo. Nesse período, o filósofo distancia-se profundamente de suas posições anteriores, expressas no Tractatus Logico-Philosophicus ${ }^{4}$. Em efeito, o pensamento do Segundo Wittgenstein, cuja obra mais conhecida é Investigações filosóficas, anuncia o fim da busca pela essência, isso é, de uma essência como propriedade comum a toda a linguagem (CONDÉ, 1998, p. 92). Desse modo não existiria a linguagem, mas simplesmente linguagens, ou seja, “[...] diferentes usos das expressões linguísticas em diferentes jogos de linguagem [...]" (CONDÉ, 1998, p. 92).

$\mathrm{Na}$ filosofia inaugurada por Investigaçôes filosóficas, Wittgenstein argumenta que os critérios que fornecem o significado são dados pelo uso que fazemos das expressões nos diversos jogos, isto é, nas diferentes formas de vida (CONDÉ, 1998, p. 65). Desse modo, as expressões adquirem funções diferentes de acordo com o contexto em que são empregadas, o que modifica, portanto, o que se quer dizer com elas. Assim, não caberia perguntar qual o significado de uma palavra, visto que, embora essa questão nos direcione 
para a elaboração de uma resposta única, ela possui inúmeras respostas. Sendo assim, "[...] significações linguísticas constituem um fenômeno social, e esse ponto é crucial para que a concepção semântica seja substituída pela concepção predominantemente pragmática [...]" (CONDÉ, 2004, p. 47).

Entretanto, como podemos saber o que condiciona o modo de uso de uma expressão? Como podemos saber em que sentido ela está sendo usada? A compreensão dessas questões nos encaminha para outra noção relevante na obra de Wittgenstein: a noção de jogos de linguagem.

Os “[...] jogos de linguagem podem em geral ser concebidos como sistemas localizados de regras lógico-gramaticais determinadoras dos usos das expressões que neles incorrem [...]" (COSTA, 2002, p. 40). O que caracteriza um jogo de linguagem é que ele é parte de uma forma de vida, sendo primariamente praticado em meio ao contexto social em que vivem os falantes. Assim, “[...] ao jogo pertencem não só as palavras, mas os participantes, os objetos e outros elementos contextuais [...]" (COSTA, 2002 , p. 40). Portanto, respondendo à questão anteriormente proposta, o que condiciona o modo de uso de uma expressão em certa ocasião é o seu uso correto em um dado jogo de linguagem.

Em consonância com sua perspectiva teórica, Wittgenstein não está preocupado em definir o que são jogos de linguagem (CONDÉ, 2004, p. 53). Seu interesse consiste em apresentar exemplos de diversos jogos, tais como: comandar e agir segundo um comando, relatar um acontecimento, inventar uma história. Considera que as conexões que existem entre diferentes jogos de linguagem são como semelhanças existentes entre membros de uma família.

Em Investigações filosóficas, Wittgenstein repele questões do tipo "O que é o conhecimento?” ou “o que é a linguagem?", pois entende que na formulação de tais questões os filósofos estariam procurando fantasmas ao pretenderem encontrar "[...] uma essência ou algum tipo de fundamentação ontológica invariável do conhecimento ou da linguagem [...]” (CONDÉ, 1998, p. 91). Nessa direção,

[...] ao filósofo não cabe fazer perguntas por essências metafísicas do tipo 'o que é...?', mas cabe a ele analisar como são usadas tais expressões (conhecimento, linguagem, etc.) nos diversos contextos linguísticos em que aparecem [...] (CONDÉ, 1998, p. 91). 
Em sua concepção da linguagem, Foucault, partilha das descobertas realizadas pelo austríaco no campo da linguagem:

[...] questões como "não perguntar 'o que é isso?" mas, sim, "perguntar como isso funciona?", ou "aquilo que está oculto não nos interessa" - que equivale a dar as costas à Metafísica - , ou "a verdade é aquilo que dizemos ser verdadeiro" - que equivale a dizer que as verdades não são descobertas pela razão, mas sim inventadas por ela - são comuns aos dois filósofos [...] (VEIGA-NETO, 2005, p. 108-109).

Compreende-se, então, que Foucault não vê a linguagem “[...] como um instrumento que liga o nosso pensamento à coisa pensada, ou seja, como um instrumento de correspondência e como formalização da arte de pensar [...]", mas “[...] assume a linguagem como constitutiva do nosso pensamento e, em consequência, do sentido que damos às coisas, à nossa experiência, ao mundo [...]” (VEIGA-NETO, 2005, p. 107). Tais considerações são importantes à medida em que nosso interesse está voltado para os sentidos que damos ao mundo. E, mais especificamente, nesta pesquisa, para os sentidos que os sujeitos que dela participaram - entre os quais nos incluímos - dão ao mundo em que vivem.

As noções advindas do pensamento de Foucault, de Bauman e de Wittgenstein, aqui brevemente esboçadas, serão aprofundadas nas próximas seções, quando da apresentação dos caminhos empíricos do estudo e dos resultados obtidos com o exercício analítico realizado.

\section{CAMINHOS EMPÍRICOS}

Nesta seção apresentamos a parte empírica do estudo. A discussão levada a efeito abrange a descrição do lócus da pesquisa, de seus participantes e dos procedimentos metodológicos utilizados no estudo.

\section{O lócus e os participantes da pesquisa}

A parte empírica da pesquisa foi desenvolvida com crianças da Escola Santa Marta, situada na divisa do bairro Santa Marta e o Loteamento Tancredo Neves em São Leopoldo, RS, município que integra a região 
metropolitana de Porto Alegre, capital do estado do Rio Grande do Sul. O lócus da investigação foi o bairro Santa Marta e a escola ali localizada, de mesmo nome. O bairro está situado em uma região marcada por subidas íngremes. Quando da realização da pesquisa, muitas dessas subidas estavam sendo capeadas pelo asfalto que, enfim, ali recém chegava. Não havia calçadas para a circulação de pedestres. Pessoas, carros, animais e carroças dividiam o mesmo espaço de circulação. $\mathrm{Na}$ entrada do bairro, as casas eram então diferenciadas umas das outras. Não havia nenhum padrão arquitetônico e os terrenos pareciam ter tamanhos díspares, como se tivessem sido divididos aleatoriamente no processo de ocupação do lugar. Geralmente limitados por cercas de madeira não retilíneas, os pátios abriam-se ao olhar alheio. Pelos vãos dos sarrafos avistava-se um pouco do privado de cada família. Roupas desbotadas e puídas nos varais, brinquedos sujos e quebrados e materiais recicláveis espalhados pelo chão, cachorros e gatos magros, carroças e "carretinhas" utilizadas na catação, cavalos e pequenas hortas diziam do dia a dia dos que ali habitavam.

Próximo à escola, um cenário um pouco diferente: as pequenas casas de cores fortes e chamativas possuíam o mesmo padrão arquitetônico. Os pátios eram do mesmo tamanho e ainda que não houvesse calçamento havia espaço para a circulação de pedestres. Algumas dessas casas já tinham sido "personalizadas" por seus moradores: "puxadinhos" serviam de garagem, cozinha ou quartos, áreas foram ampliadas, cercas de madeira e até pequenos estabelecimentos comerciais integravam a paisagem.

Em suas narrativas, pais e alunos, de modo recorrente, mencionaram serem oriundos de municípios do interior dos estados do Rio Grande do Sul ou do Paraná e que, em sua cidade de origem, desenvolviam atividades ligadas ao meio rural. Falaram sobre a tentativa empreendida, por algumas famílias, de manter, na cidade, os hábitos cultivados "lá fora", como a criação de animais. Não raras vezes, os alunos contavam sobre porcos ou galinhas criados em casa, abatidos para alguma comemoração ou almoço de domingo, ou ainda sobre a venda do leite produzido pelas vacas que criavam. Os adultos diziam ter se deslocado para São Leopoldo em busca de "oportunidades para uma vida melhor". Entretanto, encontraram na periferia da cidade, onde puderam se instalar, principalmente falta de saneamento básico, violência, subemprego, desemprego e o lixo, que foi se tornando o sustento, a comida e a sobrevivência de muitos. E, enquanto o 
lixo puder dar-lhes isso, disseram que ali ficariam. Transitoriamente, como os "vagabundos" referidos por Bauman (1998, p. 114). Para o autor, turistas são as pessoas desejáveis, aquelas que viajam porque querem, que "[...] realizam a façanha de não pertencer ao lugar que podem estar visitando [...]", pois "[...] é deles o milagre de estar dentro e fora do lugar ao mesmo tempo [...]” (BAUMAN, 1998, p. 114). Ao contrário do turista, que está em movimento porque quer, o "vagabundo" não viaja por livre escolha. Muitos talvez até se recusassem a estar em movimento se não fossem impelidos a isso. Contaram suas histórias de migrantes, que pareceram não se encerrar no bairro Santa Marta.

A vida no bairro girava em torno dos processos de coleta, separação e a venda de resíduos sólidos para galpões de reciclagem ali existentes, e o trabalho na cooperativa do setor de triagem do aterro sanitário (nomeado pelos catadores de "usina de reciclagem"), ali instalado. O local recebia, em 2008, aproximadamente 110 toneladas de lixo domiciliar por dia, oito toneladas de lixo de terceiros e lixo hospitalar. Além da cooperativa, no aterro atuavam a empresa SL Ambiental, que possui a concessão do serviço por um período de 20 anos, e a prefeitura de São Leopoldo, responsável pela pesagem e pagamento dos resíduos domiciliares, recolhidos diariamente no município. Das 110 toneladas de lixo domiciliar recebidas diariamente no aterro, em torno de $8 \%$ do total era separado e destinado para a reciclagem.

O trabalho na usina era semelhante àquele praticado pelos catadores de rua. O caminhão do lixo chegava e primeiramente era pesado. Após, largava sua carga no que eles chamavam de "fosso", que nada mais era do que o pátio próximo ao pavilhão onde era realizada a triagem. Em seguida, um operador manipulava uma máquina com uma espécie de garra, que ia colocando o lixo na esteira. Os homens e mulheres que ali trabalhavam, dispostos lateralmente ao longo dessa esteira, realizavam a separação do material. Enquanto o lixo passava, identificavam e selecionavam em torno de 60 tipos de materiais, que eram jogados em carrinhos dispostos na parte inferior do pavilhão.

Nesse momento do processo ocorria algo parecido com o que chamamos de consumo nas lojas do centro da cidade (ainda que guardadas as peculiaridades, uma dimensão oposta que demarcava a pobreza material das pessoas que ali trabalhavam). Enquanto a esteira movimentava o lixo em meio dos trabalhadores, não apenas o que seria reciclado é recolhido. 
Roupas e calçados usados, alimentos "ainda" possíveis de se consumir, cadernos e materiais escolares "aproveitáveis", objetos de decoração, flores artificiais, entre outros "tesouros" tornam se achados que deixam o limbo da lata de lixo para constituírem, novamente, objetos de desejo, objetos de consumo. Poderíamos dizer, então, que estar no início da esteira pode ter o mesmo valor de se chegar cedo a uma loja com produtos em liquidação.

Do mesmo modo, quando o aterro recebia a esperada visita dos caminhões de lixo das grandes redes de hipermercado, tudo parava, visando que todos pudessem usufruir dos produtos "novinhos" em folha que teriam ali seu destino final. Em determinados dias da semana, esses estabelecimentos destinavam ao lixo boa parte daquilo que não mais satisfazia os consumidores do centro da cidade, produtos com data de validade vencida ou próxima do vencimento, embalagens amassadas ou com pequenas perfurações, produtos danificados, enfim, tudo aquilo que afastaria do estabelecimento os consumidores capazes de responder positivamente aos atrativos do mercado. Entretanto, eram produtos que alegravam e satisfaziam àqueles que Bauman (1998, p. 24) chama "consumidores falhos", ou seja,

[...] pessoas incapazes de responder aos atrativos do mercado consumidor, porque lhes faltam os recursos requeridos, pessoas incapazes de serem 'indivíduos livres' conforme o senso de 'liberdade' definido em função do poder de escolha do consumidor $[\ldots]$.

$\mathrm{Na}$ escola sempre era possível saber quando o caminhão do hipermercado havia visitado o aterro sanitário. Naqueles dias, as mesas do refeitório eram tomadas por produtos iguais e ao pegar aleatoriamente o lanche trazido por qualquer criança, para examinar, poder-se-ia confirmar que a data de validade estava vencida. Quando perguntados sobre o que mais gostavam de receber quando vinha o caminhão do hipermercado, invariavelmente diziam que gostavam quando vinham doces, iogurtes e outras guloseimas. Dificilmente diziam preferir receber arroz e feijão. Esses alimentos básicos geralmente eram mais fáceis de serem adquiridos, seja por doações de cestas básicas, pela remuneração de familiares ou, mesmo, eram consumidos na merenda escolar. A observação desse fato foi a primeira pista para perceber o quanto o mercado produzia os desejos daquelas crianças, que queriam consumir para além de suas necessidades básicas. 
A sedução do mercado serve como grande igualadora e grande separadora da sociedade, visto que

[...] o estímulo ao consumo, para resultar eficaz, deve transmitir-se em todas as direções e dirigir-se indiscriminadamente, a todos que estão dispostos a escutá-lo. Porém, há mais pessoas que podem escutar do que as que podem responder à mensagem sedutora [...] (BAUMAN, 2000, p. 115).

Assim, aqueles que não podem responder positivamente aos apelos do mercado assistem, todos os dias, ao espetáculo proporcionado por aqueles que podem e, muito provavelmente, recebem essa mensagem como uma receita de felicidade. Uma felicidade que só pode ser alcançada pelo consumo de diversos objetos e pela manutenção de um determinado estilo de vida. Buscando alcançar essa "felicidade", as crianças que participaram da pesquisa acabavam por lançarem-se nas atividades laborais de coleta, separação e venda de resíduos sólidos para a reciclagem que serão descritas e analisadas na terceira seção do artigo.

\section{Procedimentos metodológicos}

A geração do material de pesquisa se deu a partir de atividades pedagógicas, desenvolvidas na escola Santa Marta com alunos do $2^{\circ}$ ano do ensino fundamental, acompanhadas de entrevistas individuais com oito deles. Inicialmente realizou-se uma visita ao aterro sanitário, previamente agendada. Foi observado que, durante a visita, as crianças estiveram bastante agitadas e pouco atentas às explicações dadas. Revirando o lixo espalhado no pátio, mostravam à professora o que desejavam levar pra casa. Ainda assim, na volta para a escola, em sala de aula, sabiam falar em detalhes sobre o que observaram no aterro e produziram desenhos sobre o que lá havia. Como explicar tal detalhamento se pouca atenção haviam demonstrado durante a visita? O que acontecera ali? Ao buscar respostas para essas indagações, fomos levadas a pensar que a visita tinha se constituído em uma "novidade" não para os sujeitos escolares, pois o aterro fazia parte de seu cotidiano. $\mathrm{Na}$ verdade, era a professora quem tinha curiosidade e "sabia menos" sobre o processo de separação de resíduos sólidos para a reciclagem. O olhar curioso e "estrangeiro" era o seu. A professora já havia ido anteriormente ao aterro sanitário, acompanhando outras turmas, mas foi a primeira vez que ali esteve 
usando "lentes de pesquisadora". Isso implicou em utilizar um gravador (com a devida autorização) e fazer anotações em diários de campo. No dia seguinte à visita ao aterro, a aula foi iniciada com uma conversa sobre os tipos de tratamento do lixo. Nessa conversa, de certo modo, a professora conduziu os alunos a falarem de suas experiências com a catação. Após, os alunos fizeram desenhos sobre as experiências de trabalho em que eles e seus familiares estavam envolvidos.

Em dois momentos foram utilizados os desenhos como desencadeadores da produção do material de pesquisa. Essa utilização apoiou-se, do ponto de vista teórico, no entendimento de que o desenho pode ser pensado como uma forma de expressão das coisas da vida das crianças, uma forma de presentificação e registro de suas impressões acerca do momento que estão vivendo (BUORO,1996; MARTINS; PICOSQUE; GUERRA, 1998; MOREIRA, 1984) .

A análise dos desenhos evidenciou que havia elementos que se repetiam, como o sol sorridente, centralizado na parte superior da folha, as nuvens azuis, as árvores carregadas de frutos vermelhos e, inclusive, algumas figuras humanas construídas com "palitos". Ainda que não tivesse sido dito às crianças como deveriam representar o solicitado, fomos levadas a pensar que, de certo modo, elas já "sabiam” o que podiam desenhar, as cores que deviam usar para colorir o trabalho, de modo a que ele fosse considerado um desenho "bonito". Assim, seus assujeitamentos à gramática escolar, mesmo que por mecanismos muitas vezes bastante sutis, ficavam ali expressos. Podemos refletir, então, acerca de como a gramática da escola, ou seja, as regras que devem ser seguidas, vão se instituindo, de modo eficaz, no âmbito escolar. O alfabeto e os demais cartazes da sala de aula, os livros didáticos, os livros de histórias infantis, as folhas fotocopiadas, os desenhos animados, os elogios e o semblante dos adultos que aprovam ou não os trabalhos, tudo isso acaba por conduzir o comportamento dos escolares em relação à produção artística, mesmo que linhas de fuga, movimentos de contraconduta - como o desenho em branco e preto de um aluno, representando somente os cães que circulavam no aterro - também ocorressem.

A linguagem artística desenhar ensinada na escola pode à primeira vista parecer "livre", mas, na verdade, ali se constitui em uma prática, em um jogo de linguagem, no sentido atribuído à expressão por Wittgenstein, que obedece a certas regras, as quais vão aos poucos sendo assimiladas por 
cada criança. Sendo a gramática do âmbito do social, "[...] da mesma forma que o uso condiciona a regra, essa regra, em contrapartida, determinará se o uso está correto ou não [...]" (CONDÉ, 2004, p. 89). Assim, ainda que, de certa forma, o uso seja livre, ele se guia por regras que "[...] distinguem o uso correto do incorreto das palavras [...]” (CONDÉ, 2004, p. 89).

Mas o jogo de linguagem desenhar, praticado na forma de vida escolar, faria muito mais do que "simplesmente" conduzir a conduta quanto ao que representar e ao como fazê-lo. Seria, também, uma forma de "mostrar a si", de "confessar-se", uma linguagem que possibilitaria mediar estados internos de consciência e o mundo exterior (LARROSA, 1994, p. 63). Quando uma criança desenha, pinta, move-se, dança, dramatiza, fantasia-se ou canta, estaria oferecendo uma imagem de si, “[...] estaria levando à linguagem, ao signo, embora de forma indireta, alusiva e não referencial, aquilo que ela mesma é [...]” (LARROSA, 1994, p. 64).

Refletindo acerca das atividades desenvolvidas para a produção do material da pesquisa, percebe-se que mais do que propor o desenho sobre a visita ao aterro ou sobre como viam a catação nas ruas, o que se solicitava a cada uma daquelas crianças era uma confissão. Ao realizarem os desenhos, os alunos produziam a si mesmos; ao narrarem sobre o que haviam desenhado ou se manifestarem nas entrevistas, "confessavam" suas próprias histórias a partir da gramática escolar. Ao utilizar o desenho como desencadeador das entrevistas, mais uma vez a pesquisadora pôde servir-se da professora e de suas práticas para incitar a fala de si em cada criança entrevistada. Munida de gravador, sentada frente a frente com cada aluno, uma de nós, que assumia a posição de professora/pesquisadora, deu curso a um ritual no qual esperava "produzir a verdade". A "verdade" de cada um.

Em síntese, nesta pesquisa, os ditos registrados não são tomados como "inocentes formulações" das crianças entrevistadas. Elas não apenas confessaram passagens de suas vidas. Em alguns momentos, surpreendiam a professora ao dizer coisas que ali, fora do contexto da sala de aula, a pesquisadora não esperava ouvir. Esse foi o caso do menino Marcelo que, ao ser indagado sobre o que havia desenhado, respondeu: "Que jogar lixo na rua é sujo, o planeta vai inundar tudo, vai entupir o esgoto com um monte de lixo". O que esse menino disse, assim como outros disseram, estaria conectado ao que fora dito, em sala de aula e em outros espaços midiáticos, sobre os cuidados com o meio ambiente. Provavelmente, a criança falou aquilo que supôs que a professora esperava escutar. Enfim, se tivesse havido 
alguma pretensão de produzir, com objetividade e neutralidade, um material de pesquisa, essa pretensão teria sido aniquilada.

\section{DO EXERCÍCIO ANALÍTICO}

Nesta seção apresentamos dois dos resultados obtidos a partir do exercício analítico realizado sobre o material de pesquisa. O primeiro resultado situa-se no âmbito da educação matemática, aqui compreendida como os processos educativos que ocorrem em espaços escolares e não escolares envolvendo jogos de linguagem matemáticos. O segundo resultado aponta para o modo como as crianças do bairro Santa Marta constituem-se como consumidores nas tramas do jogo neoliberal.

Jogos de linguagem das crianças catadoras: "aumentar o peso" e "comprar um real de pão"

Ao longo do trabalho de campo foi observado que as crianças, quando vendiam os materiais que arrecadavam na catação, praticavam um jogo de linguagem específico - "aumentar o peso" de resíduos sólidos recicláveis -, que explicaram: para que pudessem conseguir um ganho maior. Em um primeiro momento, essas ações poderiam parecer "simples travessuras" de crianças. Contudo, embasadas nas teorizações foucaultianas, entendemos que ali se gestavam relações de poder e que, portanto, tais jogos poderiam ser situados no âmbito de movimentos de contraconduta, tal como assinalou Foucault (2008, p. 257): “[...] são movimentos que [...] procuram, eventualmente em todo caso, escapar da conduta dos outros, que procuram definir para cada um a maneira de se conduzir [...]".

Nas entrevistas, as crianças contaram, por exemplo, que colocavam pedras dentro das latas de alumínio a serem vendidas: "Isso, bota as pedras dentro da latinha e começa a amassar bem, dai quebra as pedras e fica mais pesada a latinha. [...] Se eu não botar pedra dentro, dá um real. Se botar, dá uns três 'pila"'. Entretanto, tal ação não era tão simples de pôr em curso. Seu sucesso atrelava-se a alguns cuidados, como enfatizou Diego: "Tu tem que botar várias pedrinhas de cimento dentro da latinha e quando ela tá cheia, pegar um martelo e começar a amassar bem, dai, quando eles pesarem pra ver quanto dá, não pode fazuer barulho. Quando as pedrinhas chacoalharem e quando dá barulbo tem que amassar mais, daí dá pra botar dentro [do saco para a venda]". 
O aluno Marcelo narrou que duas outras estratégias eram frequentemente usadas. A primeira consistia em molhar algumas peças de papelão e colocá-las entre outras secas, de modo a esconder sua alteração. A segunda envolvia colocar no centro de um saco cheio de garrafas pet amassadas e vazias aquelas nas quais haviam introduzido um pouco de água.

Observamos que essas estratégias eram dotadas de pequenas sutilezas que as tornavam muito eficazes. As crianças sabiam que não poderiam ser "pegas" aumentando o "peso" dos materiais e, por conseguinte, o valor a receber por sua produção. Portanto, cuidar de detalhes - como amassar as latinhas com um martelo até que as pedrinhas não pudessem emitir nenhum som em seu interior - diziam ser de suma importância. Tais sutilezas previam até mesmo respostas "prontas", caso houvesse alguma desconfiança por parte dos compradores do galpão, como explicou um de alunos, ao ser questionado sobre o que aconteceria caso as pedrinhas dentro das latas emitissem algum som ao se manusear o material: "Daí eles veem, 'ah, isso é lacre que caiu dentro', porque os lacres quando tu vai tirar dá pra fazer crochê dá pra minha mãe e daí digo que 'tá' ali dentro".

Os diferentes jogos de linguagem que constituíam o catar das crianças do bairro Santa Marta podem ser pensados como movimentos de contraconduta, no sentido atribuído à expressão por Foucault (2008). A lógica que regia as atividades de coleta, separação e venda de resíduos sólidos para os galpões de reciclagem conduzia a conduta dos sujeitos em relação ao consumo a um nível muito inferior, devido aos valores extremamente baixos atribuídos ao produto de seu trabalho. Capturados nas tramas do jogo neoliberal, usavam o trabalho - mesmo na mais tenra idade - como passe para permanecer no jogo, ainda que numa posição bastante desprivilegiada. Mas isso não era suficiente: havia o desejo de consumir para além daquilo que seus ganhos possibilitavam. Assim, compreendemos que as crianças entrevistadas estariam, de certo modo, envolvidas em movimentos de contraconduta que visavam se opor aos baixos valores recebidos. Ao ativar suas estratégias, conseguiam até mesmo triplicar seus ganhos (como mostra a explicação de Diego, acima citada). A diferença “a mais" de valores seria o que possibilitaria um consumo maior ou menor por parte daqueles indivíduos. Seus movimentos de contraconduta podem ser considerados como resposta a problemas contingentes de suas vidas. Problemas muito 
diferentes daqueles geralmente utilizados pela escola, nas aulas de matemática (KNIJNIK; WANDERER, 2010).

No bairro Santa Marta existiam, também, peculiaridades nos jogos de linguagem praticados pelos sujeitos escolares ao comprarem pães, embutidos, frutas e carnes nos estabelecimentos comerciais. Neste artigo, analisamos o jogo que foi por nós denominado "comprar um real de pão", expressão usada por Diego quando contou: "Daí eu comprei um real de pão e o resto de mortadela". Ou, como escutamos Carina dizer: "Às vezes quando a mãe, quando a mãe pede pra mim comprar pão, dai ela pede pra mim comprar um real e cinquenta e dai eu vou lá e compro um real e cinquenta". Diferentemente dos consumidores que possuem recursos suficientes para realizar as compras necessárias de seu dia a dia e que pautam a maior parte do que desejam adquirir pela quantidade de alimentos de que necessitam, aquelas crianças falavam de compras ancoradas na quantidade de dinheiro de que dispunham. Isso, de certo modo, configurava relações diferenciadas com os produtos a serem adquiridos, como expressou uma das meninas: "Hã... Eu pego e boto... Eu, às vezes eu conto, eu boto, um real e cinquenta, dai eu boto um real e depois mais cinquenta. Cinquenta dá cinco laranjas. [...] Eu acho que é. E dai boto bastante laranja, dai ele [o vendedor] pega e tira um pouco e dai eles pesam pra mim”. O jogo de comprar realizado por essa criança estava limitado pelo dinheiro de que dispunha. Ela convocava o auxílio do vendedor, que precisava "tirar um pouco" das laranjas para que ela tivesse condições de pagar pelo produto. Assim, poderíamos dizer que mesmo aqueles que não se enquadram no perfil de "consumidores falhos" (BAUMAN, 1998) também podem precisar, em muitas situações, limitar suas compras, mas outra era a racionalidade com a qual operavam as crianças do bairro Santa Marta.

\section{Consumidores falhos, porém consumidores: nas tramas do jogo neoliberal}

A representação que é atribuída aos que, em nosso trabalho, temos denominado, de modo sintético, catadores, em geral, posiciona-os como aqueles que enfrentam, diariamente, a luta por uma sobrevivência relacionada, sobretudo, à comida de que precisam a cada dia, à roupa que precisam vestir, aos calçados de que precisam para proteger os pés, que labutam e movem um corpo que se lança em busca do refugo deixado por outros. Em outras palavras, o sentido atribuído à sobrevivência oportunizada pela atividade de 
coleta, seleção e comercialização de resíduos sólidos seria de ordem muito restrita, abrangendo somente a preservação da vida. O exercício analítico realizado com o material de pesquisa apontou para outras dimensões da relação entre catador e sobrevivência que escapam da lógica da sociedade moderna: a sociedade de produtores, que se diferencia da sociedade de consumidores (BAUMAN, 2001) ${ }^{7}$.

A sociedade de produtores apresenta-se estruturada em torno do papel do produtor, tendendo a ser normativamente regulada. Para manter-se vivo haveria um mínimo que seria preciso e tudo aquilo que ultrapassasse esse limite seria luxo, pecado (BAUMAN, 2001). Os indivíduos da sociedade de produtores precisam se posicionar num nível de conformidade, isto é, entre a linha inferior e o limite superior, no mesmo nível que o vizinho (BAUMAN, 2001, p. 90).

Por outro lado, na sociedade de consumidores a vida está voltada para o consumo, deve se bastar sem normas: "[...] ela é orientada pela sedução, por desejos sempre crescentes e quereres voláteis - não mais por regulação normativa [...]" (BAUMAN, 2001, p. 90). A ideia de luxo deixa de fazer sentido, pois se almeja que os luxos de hoje tornem-se as necessidades de amanhã (BAUMAN, 2001, p. 90). Deve-se estar sempre pronto para aproveitar a oportunidade quando ela se apresentar e para desenvolver novos desejos feitos sob medida para as novas formas de sedução. Impõe-se nunca permitir que as necessidades estabelecidas tornem dispensáveis as novas sensações ou limitem nossa capacidade de absorvê-las ou experimentá-las (BAUMAN, 2001, p. 90). Assim, na contemporaneidade, há uma inversão de ordem: a sociedade primeiramente envolve seus membros em sua condição de consumidores e não de produtores.

De certo modo, ao iniciar o estudo, esperava-se encontrar nas descrições dos participantes da pesquisa acerca da catação de resíduos sólidos para a reciclagem essa certa conformidade à qual Bauman (2001) se refere. Entretanto, ao longo da investigação, gradativamente emergiram elementos que nos conduziram em outra direção, pois constatamos que o desejo e a vontade de consumir dos catadores não estavam completamente submetidos a isso. Eles estavam inseridos numa sociedade de consumidores. Uma sociedade que, ao contrário da sociedade moderna - ou sociedade de produtores -, antes de pautar o papel do cidadão por seu engajamento na produção, primeiro precisa engajar seus membros na execução do papel de 
consumidores. Estaríamos vivendo, hoje, a Modernidade Líquida (BAUMAN, 2001). Tempos marcados pela fluidez e, portanto, pela impermanência.

Do ponto de vista histórico, Foucault (2008) mostra que a partir da década de 1980 difunde-se pelo mundo ocidental uma nova versão do liberalismo da Escola de Chicago na qual não apenas o marketing, a mídia ou a indústria cultural passam a ser responsáveis pela modelagem dos indivíduos. O Estado passa a ter papel fundamental, não no sentido de "tutelar", "regular" ou "controlar", mas no máximo de "orientar" os consumidores para que desenvolvam novas necessidades e maiores competências, "para fazerem as melhores escolhas num mercado cujas ofertas são cada vez mais variadas e cuja variação, por sua vez, é cada vez mais infinitesimal" (VEIGA-NETO, 2000, p. 197). O sujeito que se pretende formar nessa sociedade que passa a se delinear é um sujeito-cliente, que se conecta diretamente aos interesses de um Estado que não quer mais ser o provedor e o controlador da sociedade. Trata-se de formar indivíduos capazes de fazer escolhas e que saibam competir: sujeitos consumidores, "livres" o bastante para "surfar" nas ondas formadas pelo mercado. Nesse sentido, ainda que a escolarização seja a tônica do discurso de diversos tipos de governo e de boa parte do empresariado, vale lembrar que a escolarização das massas, nas últimas décadas, não apenas é importante para a lógica neoliberal, como pode ser pensada como crucial para o funcionamento do neoliberalismo (VEIGA-NETO, 2000).

Assim, cada um se veria induzido a reconhecer a si e aos outros como microempresas. Sob essa condição, caberia ao indivíduo ver-se como uma entidade que funciona desde investimentos permanentes sobre si mesmo. Disso resulta, entre outras coisas, o estabelecimento de fortes relações de concorrência entre os sujeitos (GADELHA, 2009). O indivíduo deixa de ser simples parceiro num processo de trocas para tornar-se um empresário de si, "[...] sendo ele próprio seu capital, sendo para si mesmo seu produtor, sendo para si mesmo a fonte de [sua] renda [...]" (FOUCAULT, 2008, p. 311). Nessa concepção, o salário nada mais é do que a remuneração atribuída a certo capital, ao denominado capital humano, afinal, "[...] a competênciamáquina de que ele é renda não pode ser dissociada do indivíduo humano que é seu portador [...]” (FOUCAULT, 2008, p. 312).

Entre outros elementos constitutivos do capital humano, se deve levar em conta a mobilidade, isto é, a capacidade que um indivíduo tem de 
se deslocar, de migrar. Isso porque a migração representa um custo, visto que o indivíduo deslocado ficará, durante o tempo em que se desloca, sem ganhar dinheiro, "[...] vai haver um custo material, mas também um custo psicológico da instalação do indivíduo em seu novo meio [...]” (FOUCAULT, 2008, p. 316).

Considerando as formulações de Foucault e seus comentadores (acima brevemente expostas), podemos pensar que os moradores do bairro Santa Marta, que migraram em busca de melhores condições de vida, estavam também investindo em si próprios. Do mesmo modo agiam aqueles que investiram em uma nova função, ligada diretamente ao lixo, bem como seus filhos que ali já buscavam a renda necessária para a satisfação de seus desejos de consumo.

Também podemos dizer que todos estamos sendo conduzidos por práticas e regras implícitas, que nos levam a entrar e permanecer no jogo econômico do neoliberalismo, seguindo as duas grandes regras que operam nesse jogo (LOPES, 2009). A primeira é que todos devem sempre manter-se em atividade. Ninguém pode ficar fora das malhas que sustentam os jogos de mercado. Todos ou quase todos devem ser beneficiados pelas ações de Estado e de mercado. Nesse sentido, "Estado e mercado estão cada vez mais articulados e dependentes um do outro na tarefa de educar a população para que ela viva em condições de sustentabilidade, de empresariamento, de autocontrole, etc.” (LOPES, 2009, p. 155).

Como segunda regra: "[...] todos devem estar incluídos, mas em diferentes níveis de participação, nas relações que se estabelecem entre Estado/população, públicos/comunidades e mercado [...]” (LOPES, 2009, p. 155). Ninguém pode perder tudo ou ficar sem jogar. Assim, aqueles moradores do bairro Santa Marta desprovidos das condições mínimas de sobrevivência tinham, junto ao governo, seja através dos programas assistenciais - tais como Bolsa Família e Bolsa Escola -, por meio do trabalho na cooperativa que atua na usina de reciclagem ou, ainda, nos programas sociais da prefeitura municipal, como os mutirões de limpeza pública, o passe para permanecer no jogo. Mesmo aqueles desvinculados de programas sociais do governo - como alguns catadores que atuavam nas ruas - movimentavam engrenagens de um mercado local que, ao se sustentar, sustentaria uma rede de consumo. Em contrapartida a esse Estado que provê assistência, o mercado gera o desejo de consumo e, por sua vez, 
o desejo de permanecer no jogo naqueles que pareceriam a um primeiro olhar imunes a ele.

Observamos que tais regras estruturavam a vida no bairro Santa Marta. As crianças, sujeitos de uma sociedade de consumidores, desejavam consumir, porém, ainda que "quisessem" muitas coisas, seu consumo não poderia ser movido apenas por "quereres". Esse era o caso de Cláudia. A menina contou que dava à sua mãe o dinheiro arrecadado na catação para ajudar a pagar os aparelhos de videogame adquiridos para ela e o irmão, bem como para auxiliar a pagar a conta da luz gasta com esses brinquedos. E explicou: "Nós ajudamos a gastar, nós ajudamos a pagar também". E, de certo modo, saber como usar o dinheiro ganho com seu trabalho era também uma estratégia para investir no seu pertencimento na sociedade, ou melhor, na sociedade de consumidores (BAUMAN, 2008).

A catação, de acordo com o que foi constatado na análise do material da pesquisa, era significada de diferentes formas pelos sujeitos escolares entrevistados. Catar poderia ser encarado como uma forma de arrecadar dinheiro para pagar contas, como no caso de Cláudia, bem como poderia assumir outras feições. Assim, examinando os excertos produzidos nas entrevistas realizadas com as crianças, podemos inferir que, movidas pelo desejo, elas lançavam-se nesse "submercado" que se constitui a partir do descarte, vivenciando suas atividades laborais de diferentes modos. Isso era o que ocorria, por exemplo, quando um dos meninos demonstrava um entendimento do catar como uma forma de arrecadar dinheiro para comprar objetos de desejo: "Eu vou ganhar uma carroça e um cavalo do meu cunbado [...] Eu vou ir lá, vou catar perto do Centro [...] É pra comprar roupa pra mim mesmo". Noutro caso, a catação aparece como uma forma de arrecadar in loco os objetos de desejo: "Daí eu e meu irmão fomos catar com a minha carroça, daí meu cavalo, sabe, dai eu estava indo pra chácara, dai eu vi, era um monte de panelinhas, que en tinha achado, uns brinquedos que eu levei pra areia pra brincar com elas". De forma análoga, Carlos demonstra o mesmo entendimento ao reclamar: "Minha mãe nunca acha um tênis pra mim”. Aqui, a catação se constituía como uma atividade exploratória, em que não apenas se arrecadariam materiais a serem vendidos mas também certos "tesouros" que faziam parte do imaginário e do rol de objetos de desejo que mobilizavam esses sujeitos.

Nas festas juninas da escola, observava-se que, muitas vezes, a "necessidade" era relegada a um segundo plano em relação ao desejo de 
obter objetos ou, simplesmente, de participar de brincadeiras. Usualmente, nessas festas, os alunos iam sozinhos ou acompanhando irmãos menores e carregavam consigo alguma quantia em dinheiro que possibilitaria não mais do que a compra de uma ou duas fichas no valor de cinquenta centavos cada. Essas fichas permitiam a compra de algum doce ou salgado, ou ainda a participação em alguma brincadeira em que se ganhava algum prêmio. A brincadeira mais concorrida era a Pescaria, porque ali não havia perdedores: sempre, ao final da brincadeira, o participante levava algo para casa, mesmo que fosse uma quinquilharia qualquer. Invariavelmente, as crianças, no início da festa, aglomeravam-se em frente às barracas de brincadeiras, formando longas filas. Quando suas poucas fichas chegavam ao fim, ou os brindes dessas barracas terminavam, eles passavam a rondar as barracas de "comes". Ficavam ali, então, impossibilitadas de consumir aqueles produtos - pois haviam gasto o dinheiro nas brincadeiras - , lançando olhares cobiçosos para bolos, doces, salgados e outras comidas típicas da comemoração junina no sul do país. Então, as fichas compradas pelas professoras que participavam da festa acabavam sendo doadas às crianças, para que pudessem se alimentar.

A reflexão desse episódio conduz ao entendimento de que os alunos colocavam em prática, naquela situação, estratégias muito específicas, movidos por seus desejos. Sua primeira preocupação era participar das brincadeiras e, se possível, angariar um objeto de consumo que poderia dar-lhes o status de consumidor - ainda que efêmero - conferido por sua posse. A seguir, então, através de olhares que garantiriam a generosidade das professoras, buscavam o objeto de consumo mais necessário, porém mais fugaz: o alimento. Possivelmente intuíam que não adiantaria usar a estratégia do "olhar" para convencer as professoras que trabalhavam nas barracas de brincadeiras a deixá-los brincar para ganhar um brinde, pois brincar e ganhar brindes não são considerados necessidades. Entretanto, sua própria experiência em festas juninas anteriores acabava por levá-las a perceber que, para se alimentar, tal estratégia sempre funcionava, pois esta, sim, era considerada uma "verdadeira" necessidade. Aqui, mais uma vez, podemos dizer que a participação no jogo consumista era movida muito mais pelo desejo do que pela necessidade. 


\section{COMO FECHO/ABERTURA}

Esta seção tem o intuito de estabelecer vínculos entre o que foi discutido anteriormente no texto e a educação matemática escolar, assim como formular algumas indagações diretamente vinculadas à escola, que emergiram a partir do estudo. Uma das reflexões que consideramos pertinente apresentar diz respeito ao modo como as crianças do bairro Santa Marta realizavam suas compras. Considerando o jogo de linguagem "comprar um real de pão" - acima analisado -, foi necessário estarmos atentas para não significar tais práticas como "falta", no caso, "falta de conhecimento" de conceitos largamente trabalhados na escola (tais como o quilograma). Se assim fosse, poderíamos concluir que seria essa "falta" que as conduziria a buscar outras lógicas para dar conta de suas necessidades cotidianas. Entretanto, nossa interpretação se orientou em outra direção, uma vez que entendemos que isso seria um reducionismo, produzido, possivelmente, com a formação docente ainda hoje hegemônica, na qual há uma especial valorização dos conteúdos escolares. Buscamos escapar desse reducionismo e, com isso, conjecturar que o jogo de linguagem que conformava o comprar no bairro Santa Marta carregava consigo as marcas daquela forma de vida. A menina Carina, ao ser questionada sobre seu modo de comprar, trouxe novos elementos para o entendimento da questão: "É assim, porque a minha mãe, quando tem, quando ela gasta muito, muito dinheiro, dai se tem só um pouquinho, dai a gente vai lá no mercado e compra as coisas e dai leva pra casa e dai depois que ela receber bastante, dai ela vai no Centro com a gente e compra nossas roupas". Essa fala parece oferecer algumas pistas, que nos levam à compreensão de que se a mãe tivesse dinheiro - em quantidade que pudesse até mesmo proporcionar a aquisição de roupas -, as compras talvez fossem efetuadas de outra maneira e que comprar pelo valor disponível era uma prática realizada principalmente quando o dinheiro estava muito escasso. Devido às limitações socioeconômicas da maioria das famílias do Santa Marta, essa prática poderia, então, ter se tornado recorrente entre os moradores do bairro.

Esse modo de realizar as compras situa-se na contramão daquilo que se ensina na instituição escolar e nos materiais didáticos que ali circulam. A lógica que conforma, na escola, os problemas matemáticos envolvendo comprar e vender (bastante presentes em suas práticas pedagógicas) é instituída 
por uma gramática diferente daquela que rege as compras feitas no bairro Santa Marta. Nas situações hipotéticas de comprar, que disponibilizamos a nossos alunos, os personagens compram alimentos em função da quantidade de que necessitam - muitas vezes em grandes quantidades -, não demonstrando apresentar limitações de cunho econômico. Ademais, em geral, tais situações se constituem, sobretudo, em exercícios nos quais o valor de cada produto está especificado, cabendo ao estudante apenas calcular o total. Isso nos leva a refletir sobre os significados que podemos atribuir ao "trazer a realidade para a sala de aula", formulação discutida em outro trabalho (KNIJNIK; WANDERER, 2010). Também nos leva a pensar sobre como determinadas relações de consumo são naturalizadas na forma de vida escolar. Como têm sido discutido por autores como Veiga-Neto (2000) e Costa (2006), a escola é uma engrenagem importante na manutenção da estrutura do mercado, da sociedade neoliberal em que vivemos e poucas vezes tomamos isso como objeto de reflexão. Podemos adicionar, ainda, que o desejo de consumir também pode ser acionado pela maquinaria escolar, o que motivaria os movimentos de contraconduta postos em prática pelas crianças na venda do produto de seu trabalho através do jogo de "aumentar o peso".

Ao analisarmos a participação das crianças da pesquisa na sociedade de consumidores, observamos que há um movimento que faz com que todos se sintam convocados a fazer parte do jogo, ainda que em diferentes níveis de pertencimento. E, para tanto, o Estado oferece diferentes opções, como programas sociais que garantem renda mínima, mutirões de trabalho ou, ainda, a atividade de remoção do refugo. O que ocorre aqui é o que Knijnik e Wanderer (2010), ao examinar o fechamento das escolas itinerantes do Movimento Sem Terra do Rio Grande do Sul e a matrícula dos estudantes Sem Terra em escolas urbanas, servindo-se do conceito de Hardt e Negri (2003), nomearam “inclusão diferenciada". Conforme esses autores, é impossível falar que não existem exclusões raciais, mas devemos entender que esse tipo de exclusão "[...] surge geralmente como resultado da inclusão diferenciada [...]” (HARDT; NEGRI, 2003, p. 194). Seria equivocado considerar até mesmo as leis do apartheid como "o paradigma da hierarquia racial” (HARDT; NEGRI, 2003, p. 194), já que as diferenças raciais não seriam de ordem absoluta ou natural, mas diferenças de grau. Em síntese, o "[...] racismo imperial ou racismo diferenciado integra outros em sua 
ordem e conduz as diferenças em um sistema de controle [...]" (HARDT; NEGRI, 2003, p. 195). No caso analisado por Knijnik e Wanderer (2010), quando as crianças do Movimento Sem Terra do Estado do Rio Grande do Sul foram obrigadas a frequentar um tipo de escola que se distanciava não apenas geograficamente de sua forma de vida, configurou-se um tipo de inclusão diferenciada, na medida em que os jogos de linguagem da matemática camponesa Sem Terra não fariam parte do currículo escolar. Ainda que tivessem acesso ao conhecimento oficial, esses alunos veriam seus próprios conhecimentos matemáticos serem posicionados como inferiores.

De modo análogo, podemos pensar que a inclusão de todos ou quase todos nas tramas do mercado se dá, em diferentes graus, por meio daquilo que Hardt e Negri (2003) chamaram de inclusão diferenciada. As "grandes grifes" circulavam nas ruas do bairro Santa Marta, nas roupas e sapatos encontrados no lixo ou adquiridos nos brechós e também através de imitações mais acessíveis. As mochilas das crianças, por vezes, guardavam iogurtes, biscoitos e chocolates - retirados da montanha de lixo - que nem mesmo eram encontrados no comércio local, devido ao alto valor agregado. Assim, tinha-se a percepção de que todos - ou quase todos - estavam sob o "toldo do mercado", porém observamos que os moradores do bairro Santa Marta - assim como milhares de outros que habitam este nosso mundo globalizado - não podiam participar, do mesmo modo, do "banquete consumista". O que está em jogo, nessa inclusão diferenciada dos "desprovidos" na sociedade de consumo é manter sob controle uma determinada parcela da população que poderia pôr em risco as engrenagens dessa sociedade em que vivemos. O risco é uma das características mais marcantes de nossa sociedade. "As culturas tradicionais não tinham um conceito de risco porque não precisavam disso. Risco não é o mesmo que infortúnio ou perigo. Risco se refere a infortúnios ativamente avaliados em relação a possibilidades futuras" (GIDDENS, 2000, p. 33). Dizendo de outro modo, ao manter todos - ainda que precariamente - sob o toldo do consumo, através de inúmeros programas de geração de renda e da manutenção de determinados tipos de engrenagens de remoção do refugo - como as do bairro Santa Marta - o Estado tem, em contrapartida, sob sua tutela, uma população que poderia pôr em risco as tramas sobre as quais esse Estado e o mercado se sustentam. 
Cabe perguntar, então: como a escola se insere nessas tramas? Como a escola pode produzir enfrentamentos, estratégias, movimentos de contraconduta, no sentido de não ficar subserviente à lógica neoliberal e consumista que conforma nossa sociedade? No âmbito do currículo escolar, que práticas a serviço da lógica neoliberal temos legitimado? Que linhas de fuga poderiam ser produzidas de modo a romper, mesmo que de modo bastante pontual, com tal lógica?

Essas são indagações que, nos tempos de hoje, são centrais para o campo da Educação. Este artigo não teve o propósito de encontrar respostas para elas. Limitou-se a produzir uma descrição - a mais minuciosa possível - sobre alguns aspectos da forma de vida de um grupo de crianças marcadas não só pelo pouco ou nenhum acesso a bens materiais mas também pelas atividades laborais, mesmo que informais, que desenvolvem. Apresentou algumas indicações sobre a inserção - mesmo que sob a forma de inclusão diferenciada - de crianças catadoras na sociedade de consumidores. Mostrou movimentos de contraconduta que são postos em ação por elas. Com isso, buscou se afastar de narrativas que, muitas vezes, simplificam e homogeneízam a vida de crianças como as do bairro Santa Marta.

A pesquisa também trouxe evidências de que a racionalidade que ali opera possui singularidades, como o jogo de linguagem "comprar um real de pão". Tais evidências podem contribuir para as reflexões que, na contemporaneidade, têm sido feitas sobre o currículo escolar, em especial sobre os conteúdos que o constituem, sobre a política do conhecimento que a ele subjaz, sobre a racionalidade que ali impera.

Esses foram os caminhos percorridos neste estudo. Caminhos que são do âmbito do social, do cultural e também do âmbito da escola. Caminhos que buscam escapar do idêntico, assim como de generalizações. Escolhemos tais caminhos inspiradas nas palavras de Esther Díaz (2011):

Uma alternativa ao pensamento da identidade é um pensar que percorre superfícies, que "voa baixo", que mais do que voar, caminha entre os fatos. Mostra-os. É o pensamento dos baixos fundos de Nietzsche, o pensamento da imanência de Spinoza, o pensamento dos jogos de linguagem e das formas de vida de Wittgenstein. Se no esforço para se aproximar dos fatos, abandonam-se as categorias abarcativas, começam, então, a surgir as diferenças, as singularidades, as perspectivas. 


\section{REFERÊNCIAS}

ALMEIDA, F. Q.; GOMES, I. M.; BRACHT, V. Bauman \& a Educação. Belo Horizonte: Autêntica Editora, 2009.

ANDERSSON, F. As ações do poder público municipal para o setor de reciclagem de resíduos sólidos em Porto Alegre: um estudo exploratório. 2005. Dissertação (Mestrado em Administração)Universidade Federal do Rio Grande do Sul, Porto Alegre, 2005.

ARENHART, A. B. P. Colcha de retalhos: A costura de projetos de vida no coletivo da Ecos Verde. 2006. Dissertação (Mestrado em Ciências Sociais Aplicadas)-Universidade do Vale do Rio dos Sinos, São Leopoldo, 2006.

BAUMAN, Z. O mal-estar da pós-modernidade. Rio de Janeiro: Jorge Zahar Ed., 1998.

BAUMAN, Z. Trabajo, consumismo y nuevos pobres. Barcelona: Gedisa, 2000.

BAUMAN, Z. Modernidade líquida. Rio de Janeiro: Jorge Zahar Ed., 2001.

BAUMAN, Z. Vidas desperdicadas. Rio de Janeiro: Jorge Zahar Ed., 2005.

BAUMAN, Z. Vida para o consumo. Rio de Janeiro: Jorge Zahar Ed., 2008.

BUORO, A. O olhar em construção: uma experiência de ensino e aprendizagem da arte na escola. São Paulo: Cortez, 1996.

BRASIL. Ministério da Educação. Lei n. 8069, de 13 de julho de 1990. Dispõe sobre o Estatuto da Criança e do Adolescente. Diário Oficial da República Federativa do Brasil, Brasília, DF, 16 jul. 1990. Disponível em: <http://www.planalto.gov.br/ccivil_03/leis/18069.htm>. Acesso em: 14 de jan. 2009.

CANDIOTTO, C. Foucault: uma história crítica da verdade. TRANS/FORM/AÇAO, São Paulo, v. 29, n. 2, p. 65-78, 2006.

CONDÉ, Mauro L. L. Wittgenstein: linguagem e mundo. São Paulo: Annablume, 1998.

COSTA, C. Filosofia da linguagem. 2. ed. Rio de Janeiro: Jorge Zahar Editor, 2002.

COSTA, M. V. Paisagens escolares no mundo contemporâneo. In: SOMMER, L. H.; BUJES, M. I. E. (Orgs.). Educação e cultura contemporânea: articulações, provocações e transgressões em novas paisagens. Canoas: Editora da Ulbra, 2006. p. 177-195.

DÍAZ, E. Ludwig Wittgenstein: Un pensador de la diferencia. Disponível em: < http:/ /www. estherdiaz.com.ar/textos/wittgenstein.htm>. Acesso em: 10 out. 2011.

FEITOSA, D. A. Cuidado e sustentação da vida: A interface da educação popular no cotidiano de mulheres recicladoras. 2005. Tese (Doutorado em Educação)-Universidade Federal do Rio Grane do Sul, Porto Alegre, 2005.

FISCHER, N. B. Trabalho e autonomia - construção do 'possível' entre os trabalhadores, homens e mulheres, recicladores da Associação Ecológica Rubem Berta de Porto Alegre - RS. Educação Unisinos, São Leopoldo, v. 10, p. 130-138, 2006.

FOUCAULT, M. História da sexualidade I: a vontade de saber. Rio de Janeiro: Edições Graal, 1988.

FOUCAULT, M. Ditos e escritos V. Rio de Janeiro: Forense Universitária, 2004.

FOUCAULT, M. Segurança, território, população: curso dado no Collège de France (1977-1978). São Paulo: Martins Fontes, 2008.

GADELHA, S. Biopolítica, governamentalidade e educação: Introdução e conexões, a partir de Michel Foucault. Belo Horizonte: Autêntica, 2009. 
GIDDENS, A. Mundo em descontrole. Rio de Janeiro: Record, 2000.

HARDT, M.; NEGRI, A. Empire. Cambridge: Harvard University Press, 2003.

LARROSA, J. Tecnologias do eu e educação. In: SILVA, T. T. (Org.). O sujeito da educação: Estudos foucaultianos. 4. ed. Petrópolis: Vozes, 1994. p. 35-86.

KNIJNIK, G.; WANDERER, F. Mathematics Education and Differential Inclusion: A Study about Two Brazilian Time-Space Forms of live. ZDM, Berlin, v. 42, n. 3-4, p. 349-361, 2010. http://dx.doi.org/10.1007/s11858-010-0247-8

LOPES, M. C. Políticas de Inclusão e Governamentalidade. Revista Educação \& Realidade, Porto Alegre, v. 34, n. 2, maio/ago. 2009.

MARTINS, M. C. F. D.; PICOSQUE, G.; GUERRA, M. T. Didática do ensino da arte: a língua do mundo: poetizar, fruir, conhecer arte. São Paulo: FTD, 1998.

MOREIRA, A. A. A. O espaço do desenho: educação do educador. São Paulo: Loyola, 1984.

MELLO, M. B. O Lixo como contexto: as crianças catadoras e seus saberes. Movimento, Niterói, v. 4, p. 56-67, 2003.

MICHELOTTI, F. C. Catadores de "lixo que não é mais lixo": um estudo da dimensão do reconhecimento social a partir de sua experiência de organização coletiva no Rio Grande do Sul. 2006. Dissertação (Mestrado em Ciências Sociais)-Universidade Federal do Rio Grande do Sul, Porto Alegre, 2006.

SARAIVA, K.; VEIGA-NETO, A. Modernidade líquida, capitalismo cognitivo e educação contemporânea. Revista Educação \& Realidade, Porto Alegre, v. 34, n. 2, maio/ago. 2009.

SOUZA, M. C. R. F. Gênero e Matemática(s) - Jogos de verdade nas práticas de numeramento de alunas e alunos da Educação de Pessoas Jovens e Adultas. 2008. Tese (Doutorado em Educação)Universidade Federal de Minas Gerais, Belo Horizonte, 2008.

VEIGA-NETO, A. Educação e governamentalidade neoliberal: novos dispositivos, novas subjetividades. In: BRANCO, G. C.; PORTOCARRERO, V. (Orgs.). Retratos de Foucault. Rio de Janeiro: Nau, 2000. p. 179-217.

VEIGA-NETO, A. De geometrias, currículo e diferenças. Educação e Sociedade, Campinas, v. 23, n. 79, p. 163-186, ago. 2002.

VEIGA-NETO, A. Foucault \& a Educação. 2. ed. Belo Horizonte: Autêntica, 2005.

\section{NOTAS}

${ }^{1}$ Neste artigo optou-se pelo uso da expressão catação de resíduos sólidos recicláveis - ou simplesmente catação - para indicar os processos de coleta, separação e venda desses materiais. Com isso, houve a intenção de introduzir no texto o modo de as crianças que participaram da pesquisa nomearem as práticas associadas ao lixo nas quais elas mesmas ou seus familiares estavam envolvidos.

2 Observarmos que na pesquisa ficavam evidentes questões relativas ao trabalho infantil que contrariam o que diz, por exemplo, o artigo 60 do Estatuto da Criança e do Adolescente (BRASIL, 1990): “[...] é proibido qualquer trabalho a menores de quatorze anos de idade, salvo na condição de aprendiz [...]”. Entretanto, ainda que sejamos sensíveis a isso, tanto 
pela restrição do espaço quanto por ser outra a problematização que guia essa investigação, não realizamos aqui uma análise acerca do trabalho infantil a que estavam submetidos os participantes da pesquisa.

${ }^{3}$ Vale lembrar que por conduta Foucault designa

[...] a atividade que consiste em conduzir, a condução, [...] também a maneira como uma pessoa se conduz, a maneira como deixa se conduzir, a maneira como é conduzida e como [...] ela se comporta sob o efeito de uma conduta que seria ato de conduta ou de condução [...] (FOUCAULT, 2008, p. 255).

${ }^{4}$ No Tractatus, o filósofo austríaco concebe “[...] uma metafísica do silêncio, na qual a linguagem, embora capaz de descrever os fatos do mundo, se revela essencialmente inadequada para lidar com a face metafísica da realidade [...]" (CONDÉ, 1998, p. 13). Nessa obra há o entendimento de que o que ocorre no mundo pode ser expresso pela linguagem, isso devido à existência de uma forma lógica em comum entre realidade e linguagem (CONDÉ, 1998, p. 66). À linguagem caberia o papel de representar o mundo.

5 As carroças eram puxadas por cavalos e carretinhas era como denominavam os pequenos carrinhos de tração humana usados no trabalho de catação.

6 Ainda que, como acima mencionado, os desenhos não tenham sido utilizados como material analítico propriamente dito, uma vez que o jogo de linguagem desenhar foi proposto como um propulsor da produção do material de pesquisa, avaliamos ser pertinente tecer, nos parágrafos que se seguem, algumas considerações teórico-metodológicas sobre o referido jogo.

7 Ao apresentar esta análise, estamos cientes de que ela constitui somente uma dentre múltiplas possibilidades interpretativas.

Recebido: 29/11/2011

Aprovado: 09/04/2012

Contato:

Universidade do Vale do Rio dos Sinos Programa de Pós Graduação Em Educação Av. Unisinos, 950, Cristo Rei CEP $93022-000$ São Leopoldo, RS Brasil 